\title{
PROGRESSIVE MULTIFOCAL LEUKOENCEPHALOPATHY ASSOCIATED TO MULTIPLE SCLEROSIS THERAPIES: REVIEW OF THE LITERATURE
}

\author{
Ana-Maria Vladila1, Dan-Andrei Mitrea1, Sanda Maria Nica ${ }^{1,2}$, Ioan Buraga, \\ ${ }^{1}$ Department of Neurology, Colentina Clinical Hospital, Bucharest \\ 2 "Carol Davila" University of Medicine and Pharmacy", Bucharest
}

\begin{abstract}
Progressive multifocal leukoencephalopathy $(\mathrm{PML})$ is an opportunistic infection associated with the reactivation of the JC virus, causing a severe demyelination within the central nervous system in patients with immunosuppression caused by disease or secondary to use of drugs. Several therapies used in the treatment of MS have reported cases of associated PML, most cases being related to Natalizumab treatment.

In this article we review specific MS medication with a reported risk for PML, and also revise PML epidemiology, pathogenesis, treatment and available approaches on therapy in patients at high risk for developing this infection.
\end{abstract}

Keywords: PML, JC virus, multiple sclerosis, Natalizumab, Fingolimod, dimethyl fumarate, alemtuzamab, PCR, cerebral MRI demyelinating lesion, plasma exchange, Mirtazapine

\section{INTRODUCTION}

PML is an opportunistic infection associated with the reactivation of the John Cunningham Virus (JCV), causing a severe demyelination within the central nervous system. (1). The JC is a ubiquitous non-enveloped double-stranded DNA-virus of the Polyomaviridae genus, $50-86 \%$ of general population having positive antibodies. $(1,4,16,37)$

The infection was initially described in 3 patients with lymphoproliferative disorders in the 1960 s, afterwards reported in patients with severe immunosuppression caused by malignancies, granulomatous inflammatory diseases, solid organ transplant recipients or secondary to the use of certain immunosuppressing drugs. Most cases were associated with HIV-infection prior to the introduction of highly aggressive antiretroviral therapy (HAART) when its' prevalence among these patients dropped from $5 \%$ to $1.3 \%$. (2)
Other neurological disorders related to the reactivation of the JC virus have been described including JC encephalopathy, JC meningitis and JC cerebellar granule cell neuronopathy. $(4-8,16,37)$

Interest in $\mathrm{JC}$ infections and especially PML has increased considerably since 2005 , when first cases were described in patients with Crohn and multiple sclerosis treated with Natalizumab.

In contrast to the classic PML, the form associated to Natalizumab treatment and HAART has an important inflammatory component described as the immune reconstitution inflammatory syndrome (IRIS) demonstrated by contrast enhancement of PML lesions on brain MRI; even if this form is considered to have a better prognosis, high mortality is still a concern with a reported rate of $23 \%$ among these patients. $(4,9-10,37)$

In the past years, new treatments for multiple sclerosis were introduced, with good control on disease clinical and imagistic activity, but emerging evidence report cases of PML associated with these drugs. 
After reviewing the available literature we focus on multiple sclerosis disease modifying therapies with reported cases of PML, PML pathology, diagnosis and available treatment.

\section{THEORIES ON PML PATHOGENESIS}

The exact mechanism of infection is unknown and many theories are emerging. It is considered that the primary infection occurs during childhood and young adulthood via a respiratory or oropharyngeal route, with minimal or no symptoms. JC virus appears to bind to the cell surface by sialic acid receptors which are linked to the serotonin receptor 5HT2a. This is followed by blood dissemination of the virus and establishment in lymphoid organs and kidneys, where the virus remains in a latent form, having intermittent urinary excretion. The virus has the ability to rearrange its genome into a neurotropic strain. It is considered that in patients with severe cellular immunosuppression determined by disease or secondary to the use of medication, the virus with a high tropism for the brain, migrates and infects predominantly the oligodendrocytes, determining the characteristic demyelinating lesions because of the ineffective immune surveillance and elimination of the infection. $(37,38)$

Demyelinating lesions involve the subcortical white matter, white and grey matter junction and also the cortex, the intracortical ones being of small dimensions and numerous as described in the latest pathology studies. $(4,11)$

Another hypothesis points to the role of B lymphocytes in the pathogenesis of PML, suggesting that these cells could be the site of the virus establishment, replication and molecular shift to the neu- rotropic strain, thus providing the way for the virus to enter the brain, a theory also supported by the high prevalence of PML in B-cell disorders and by Natalizumab's mechanism of action. $(1,4,11,16)$

\section{CLINICAL AND IMAGING FEATURES OF PML}

PML usually manifests as subacute neurological deficits in a patient with severe immunosuppression, in our case a patient with Natalizumab treatment and with risk factors associated; depending on location of the lesion within the CNS, initial symptoms may vary, but altered mental status, motor deficits (hemiparesis or monoparesis), limb ataxia, gait ataxia, visual symptoms, aphasia or seizures should alert the attending physician to further investigate these patients. As the name implies, the evolution is progressive and multifocal, has a high mortality rate and survivors are left with moderate to severe disability in nearly $80 \%$ of cases. $(1,4$, $12,16,37)$

Natalizumab-associated PML has a better prognosis than PML in HIV-patients, survival with treatment being reported in $75 \%$ of diagnosed cases. $(12,16,37)$

PML has a typical appearance on MRI, comprising symmetrical or asymmetrical multifocal areas of demyelinization that do not conform to vascular territories, nor have surrounding edema in the classical form; they usually don't enhance, except in the cases associated with the immune reconstitution inflammatory syndrome, typical of Natalizumab-associated PML, when also mass effect can be present. PML lesions may be hyperintense on DWI, uni- or bilateral and preferentially located in the periventricular areas, subcortical white matter,

TABLE 1. Clinical and MRI differences in MS relapse versus $P M L$ - Modified from (16) and (37)

\begin{tabular}{|c|c|c|}
\hline Characteristics & MS Relapse & PML \\
\hline $\begin{array}{l}\text { Clinical } \\
\text { presentation }\end{array}$ & $\begin{array}{l}\text { Diplopia, optic neuritis, paresthesia, mono-, } \\
\text { hemi- or paraparesis }\end{array}$ & $\begin{array}{l}\text { Commonly behavioral, psychiatric, retrochiasmal visual deficits, sei- } \\
\text { zures, aphasia, hemiparesis }\end{array}$ \\
\hline Evolution & $\begin{array}{l}\text { Hours to days, normally stabilizes and usually } \\
\text { can resolve without treatment }\end{array}$ & Progressive over days to weeks \\
\hline Appearance & Smaller, ovoid-shaped, well defined lesions & $\begin{array}{l}\text { Large, uni/multifocal white matter lesions }(>3 \mathrm{~cm}) \text {, with sharp bor- } \\
\text { ders towards grey matter and ill-defined toward the white matter; } \\
\text { often surrounded by smaller T2 punctate lesions }\end{array}$ \\
\hline Location & $\begin{array}{l}\text { Supratentorial: in the periventricular white } \\
\text { matter - Dawson's fingers, deep white matter, } \\
\text { juxtacortical or infratentorial: cerebellum, spi- } \\
\text { nal cord, the brainstem }\end{array}$ & $\begin{array}{l}\text { Predominantly in the subcortical white matter of the frontal lobes, } \\
\text { can affect parietal, occipital lobes, can follow white matter tracks, } \\
\text { cross the corpus callosum; internal capsule, rarely within the brain- } \\
\text { stem or cerebellum, uncommon in the spinal cord }\end{array}$ \\
\hline FLAIR & Hyperintense equal to T2 appearance & $\begin{array}{l}\text { Hyperintense, more sensitive for detection of PML lesions in subcor- } \\
\text { tical areas }\end{array}$ \\
\hline Mass effect & Larger lesions may show slight mass effect & Mass effect not typical; PML-IRIS may exhibit edema and mass effect \\
\hline $\begin{array}{l}\text { Contrast } \\
\text { enhancement }\end{array}$ & $\begin{array}{l}\text { Acute lesions will enhance; C-shaped or nodu- } \\
\text { lar enhancement }\end{array}$ & $\begin{array}{l}40-50 \% \text { of Natalizumab - associated PML enhance; pattern may be } \\
\text { patchy, punctate, or rim-like }\end{array}$ \\
\hline
\end{tabular}


brainstem, pyramidal tracts, and cerebellum or may involve the corpus callosum; of note, the cortical areas of demyelination are not seen on conventional MRI. (4,13-16,37)

In multiple sclerosis patients a very important and in the same time difficult task for the neurologist is to distinguish between a disease relapse and PML initial symptoms; the following table consists of clinical and imaging data that could give physicians a hint when discerning between the two entities (Table 1).

\section{PML DIAGNOSIS}

In patients with a suggestive clinical and imagistic setting, in our case MS patients with Natalizumab treatment and risk factors associated with this medication, PML can be diagnosed using the polymerase chain reaction to demonstrate the presence of the JCV DNA in the CSF; the PCR has a sensitivity of $72-92 \%$ and a specificity of $92-100 \%$. (16)

Following the algorithm (Fig. 1), in the case of negative PCR, the recommendation is to take into consideration differential diagnosis, but also to repeat the evaluation; in the case of unrevealing results, brain biopsy should be performed, this remaining the gold standard for definite diagnosis - sensitivity of $64-96 \%$ and a specificity of $100 \%$, but rarely needed. $(16,17,37)$

\section{NEW MULTIPLE SCLEROSIS TREATMENTS ASSOCIATED WITH PML}

Widely used immunomodulatory agents for treatment of RRMS including IFN- $\beta 1 \mathrm{a}$, IFN- $\beta 1 \mathrm{~b}$, and glatiramer acetate, were proved to have beneficial effect on patients suffering from multiple sclerosis. No risk of PML was demonstrated after prolonged use of this medication, however, with the introduction of new efficient therapies, the development of PML became a concern for these patients.

Drugs associated with PML in MS patients include natalizumab, fingolimod and dimethyl fumarate. Another drug used for treatment of RRMS, Alemtuzumab, was linked to cases of PML in other diseases. (38)

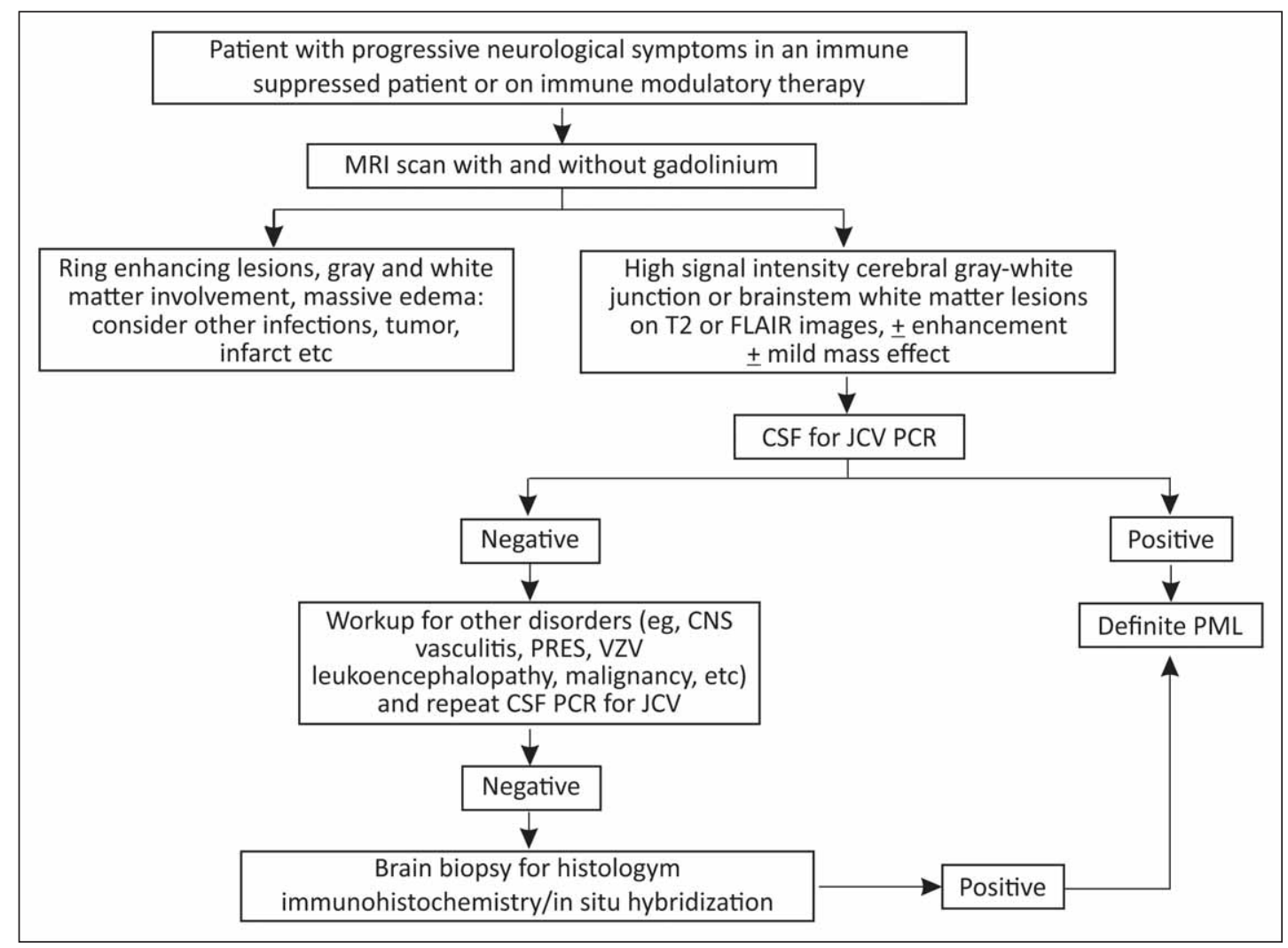

FIGURE 1. Algorithm for diagnosing progressive multifocal leukoencephalopathy FLAIR: fluid-attenuated inversion recovery; JCV: JC virus; PML: progressive multifocal leukoencephalopathy; PRES: posterior reversibile encephalopathy syndrome; VZV: varicellazoster virus. 


\section{Natalizumab}

Natalizumab was first introduced as treatment for RRMS in 2004, shortly removed from the market due to PML development, but because of its proven efficacy $-68 \%$ decrease in relapse rate and $40 \%$ reduction of disability development - it was re-introduced in 2006.

Natalizumab is a humanized monoclonal antibody targeting VLA4-Integrins ( $\alpha 4 \beta 1$-integrin), inhibiting leukocytes adhesion and transmigration across the blood-brain barrier into the central nervous system, thus preventing the specific inflammatory events leading to the development of multiple sclerosis lesions. It was proven that Natalizumab also affects active central nervous system inflammation, mediated by the leukocytes already present in the CNS, by blocking the interference between $\alpha 4 \beta 1$ integrin-expressing leukocytes and extracellular matrix proteins such as fibronectin and osteopontin (14-16,18,38)

By September 2015, 142,000 patients with MS received treatment with Natalizumab, and 585 cases of PML were reported so far. This led to an overall PML incidence in Natalizumab receiving patients of $4.12 / 1,000$ cases (95\% CI 3.71 to $4.36 / 1,000$ patients).

Specific risk factors are now known to increase the incidence of PML in this group of patients. These include: prior history of JCV infection by detecting the presence of JCV antibodies; prior exposure to immunosuppressing therapy and the use of Natalizumab for more than 24 months, the latter being proven to increase the risk of developing PML from $1 / 10,000$ to $1 / 1,000$ following 2 years of treatment. The last risk factor is the titre level of JCV antibodies in the blood, a level of below 1.5 being considered as low risk for developing PML (Fig. 2). (19,37)

Up to this moment, $23 \%$ of the 585 patients diagnosed with PML have died and $77 \%$ are alive with varying disability levels.

Even though PML incidence is considered low, current protocols recommend periodic monitoring by MRI and serological testing of JCV antibodies at 6 months of treatment. Alternative therapies should be considered if seroconversion occurs and the patient has a high-risk profile (JCV antibodies $>1.5$, treatment with Natalizumab $>24$ months). $(4,16,19,27,37,38)$

\section{Natalizumab-associated PML treatment}

To date there is no specific treatment of PML, all the measures and medication used in the setting of this disease has the purpose of restoring the patient's immune system in order to naturally fight and eliminate the virus.
In MS patients on Natalizumab, this means the immediate discontinuation of Natalizumab followed by a five-day regimen of plasma exchange in order to increase the elimination of the medication from the patient's system; taking into consideration the probable role of the 5HT1A receptor in the infection, mirtazapine is recommended in addition, using a daily dosage of $15-45 \mathrm{mg}$ (grade $2 \mathrm{C}$ recommendation). (22,37)

In these patients with PML, IRIS should be expected during the $3-6^{\text {th }}$ week after plasma exchange, in its most severe form producing a rapid neurological degradation and evidence of extensive brain swelling on MRI; only in the setting of both - neurological and MRI deterioration, should glucocorticoids be added to the therapy. Multiple regimens of high dose intravenous glucocorticoids can be used, dexametasone $32 \mathrm{mg}$ /daily divided in 4 doses for 2 weeks or methylprednisolone $1 \mathrm{~g}$ /daily for 5 consecutive days, followed by slow oral taping of the treatment. $(16,20,21)$

Maraviroc, a CCR5 receptor antagonist used in the treatment of HIV, has results documented in 2 case reports: one in a patient treated for PML-associated to Natalizumab use and another one in a HIV-positive patient, the used dosage in both cases being $600 \mathrm{mg} /$ daily. In a third case of natalizumabassociated JCV granule cell neuronopathy, maraviroc treatment was not associated with improvement; new data is needed to document the possible use of maraviroc in treating these patients. (37)

A new approach on this potentially fatal disease is coming from Prof. Roland Martin's group from the University of Zürich, who is working on developing an active vaccine: "We made a major breakthrough, we managed to isolate antibody producing cells from a patient who survived PML and use them to produce neutralizing antibodies against the JC virus. These human antibodies have a major advantage: they recognize the most important mutants of the JC virus that can cause PML. They now make promising candidates for the development of a treatment for PML." $(23,24)$

The prognostic factors identified so far are: patient's age, the level of MS disability previous to the infection and early detection in the form of radiologically isolated PML; localized disease on MRI - unilobar versus multilobar infection has an overall survival of $85 \%$ versus $66 \%$ for the multilobar form. $(16,37)$

PML associated with Natalizumab treatment has a better prognosis than that occurring in HIV-patients, $80 \%$ of those diagnosed remaining alive one year after diagnosis but more than half of them with moderate to severe neurological disability. 


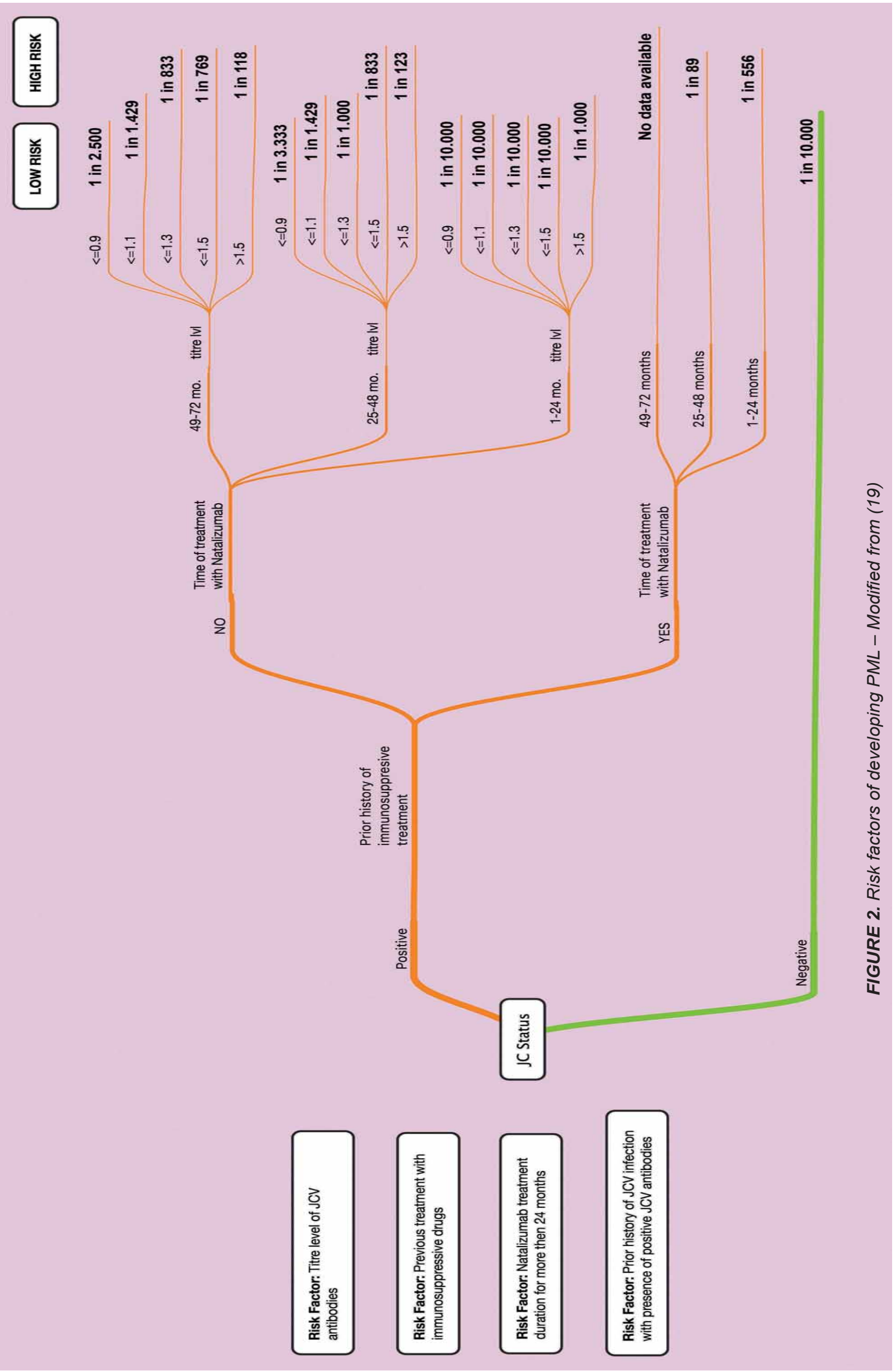




\section{Fingolimod}

Fingolimod is an oral approved first line therapy for RRMS in 2010. The molecule is phosphorylated to its active form resembling sphingosine 1-phosphate $(\mathrm{S} 1 \mathrm{P})$, and acts as an agonist to $\mathrm{S} 1 \mathrm{P}$ receptors (S1P1, S1P3, S1P4, S1P5). S1P is a cell membrane component that makes-up to $25 \%$ of the lipid in the myelin sheath and regulates cell proliferation and movement but also has pronounced effects on immune function and lymphocyte migration.

Fingolimod's high affinity to S1P receptors induces their down-regulation, thus blocking the lymphocytes within the lymphoid tissue and reducing auto-aggressive cell infiltration into the central nervous system. It also crosses the blood brain barrier and, in vitro studies have shown that when it binds to oligodendrocytes it protects them from cell death and also promotes processes involved in remyelination. $(25,26)$

To date 3 cases of PML related to Fingolimod treatment were reported in an estimated 125,000 MS patients receiving this treatment.

The first PML case identified was in early 2015 in a 49 years old patient with a history of MS of 5 years, had previous treatment with interferon and in the last.

4 years was treated with Fingolimod. Lesions suggestive for PML were described on a routine MRI, while no clinical signs were present; the lumbar puncture with PCR analisys of CSF for JCV DNA was positive. (38)

Another PML case, also reported in 2015, was in a 54 years old male that had MS for 14 years, had DMT with interferon for 12 years (IFN- $\beta 1 b$ ) and had JCV positive antibodies since 2012. He also had a history of ulcerative colitis treated with mesalamine. He was switched to Fingolimod and received treatment for 2.5 years before presenting to the ER accusing cognitive impairment, motor inability and spastic hemiparesis, symptoms that occurred 3 weeks before admission. Of note in this case is that the patient presented lymphopenia since the beginning of his treatment with Fingolimod $\left(330-550 / \mathrm{mm}^{3}\right)$.

In both cases fingolimod was discontinued.

The third case of PML was recently reported in a patient diagnosed with Crohn's disease and a history of colorectal cancer for which he received chemo and radiotherapy; no additional details are available at this moment.

So far, 11 other cases of PML are reported after switch from Natalizumab to Fingolimod. All patients had exposure to Natalizumab for a median of
5 years and, all of them presented positive JCV antibodies prior to switching to Fingolimod. Therefore it is difficult to determine whether the infection was related to the new therapy or was subsequent to the Natalizumab use. $(25,26,38)$

\section{Dimethyl Fumarate}

Dimethyl fumarate is an oral administered therapy approved as first line treatment for RRMS. The molecule has immunomodulatory and neuroprotective effects by activating the nuclear factor (erythroid-derived 2)-like 2 (Nrf2) antioxidant response pathway, therefore promoting the cells anti-oxidant and protective mechanisms. An in vitro model studied the effects of dimethyl fumarate and concluded that it actually causes a short period of oxidative stress resulting in intraneuronal synthesis of glutathione antioxidant (GSH) mediated through the Nrf2 pathway. Other research groups have proposed additional dimethyl fumarate actions mediated through nitric oxide, interleukins, tumor necrosis factor (TNF- $\alpha$ ) or other cytokines. (28-30)

Dimethyl fumarate has been in use for many years in treatment of dermatologic diseases; the first case of PML occurred in a patient with psoriasis. The patient was of a 42 years old female with a 5 years exposure to dimethyl fumarate $(420 \mathrm{mg} /$ daily), who presented with right 6 moths-progressive hemiparesis. MS was suspected in this case, but MRI scan revealed lesions suggestive for PML and the lumbar puncture confirmed presence of JCV antibodies; there was associated lymphopenia $\left(200 / \mathrm{mm}^{3}\right)$.

To date, 4 cases of PML were reported in psoriasis patients receiving dimethyl fumarate including the case presented above, with two of them having other possible predisposing conditions, sarcoidosis with immunosuppressive previous treatment and colorectal cancer respectively. (38)

A single case of PML was reported in a patient with definite MS receiving dimethyl fumarate. It was the case of a 54 years old female, that had a 12 years history of MS, underwent treatment with glatiramer acetate for 2 years, then was switched to dimethyl fumarate when she was enrolled in the DEFINE trial. She received $240 \mathrm{mg}$ of dimethyl fumarate three times per day for 4.5 years; lymphopenia was present for 3 years $\left(290-580 / \mathrm{mm}^{3}\right)$. She had good control of her illness until 2014 when she developed gait instability, speech disturbance and had left arm uncoordinated movements. A MS relapse was considered and she was treated with methylprednisolone but with no clinical response, fol- 
lowed by plasma exchange. MRI and CSF evaluation diagnosed the patient with PML. (38)

To conclude, 155.000 MS patients received treatment with Dimethyl fumarate to this date and only one case of PML was described in these patients.

\section{Alemtuzumab}

Alemtuzumab is a monoclonal antibody that targets CD52 cell surface glycoprotein. It is indicated as treatment in patients diagnosed with RRMS that present with inadequate response to 2 or more disease modifying therapies.

Alemtuzumab has a long-lasting effect due to its depletion of CD52 bearing B and T cell thought antibody-dependent cell-mediated cytolysis and complement-dependent cytolysis. $(31,32)$

There are no PML cases reported so far in MS patients receiving Alemtuzumab; however there are 57 patients that presented with PML after being treated with this medication for chronic lymphocytic leukemia (55) and lung transplant (2). The particularity of these cases was that PML onset was at approximately 1 month after treatment initiation. $(32,38)$

\section{High risk patients monitoring - what to do upon discontinuation of Natalizumab}

While the incidence of PML is low considering the number of MS patients that undergo DMT, it must be taken into consideration when recommending a treatment plan.

Some risk factors have already been described associated with Natalizumab treatment, this meaning that there is a need for safe and effective alternative DMT to control disease activity upon discontinuation of Natalizumab.

The TOFINGO study published in July 2015 evaluated the efficacy of switching patients from Natalizumab to Fingolimod within a specific time frame since the last infusion. 142 patients were enrolled, of which 112 (78.9\%) completed the study; they were separated into 3 groups according to the beginning of their Fingolimod treatment which was at 8,12 and 16 weeks after last Natalizumab infusion. The study concluded that initiating Fingolimod therapy at 8-12 weeks since last Natalizumab infusion is associated with lower risk of MRI and disease relapse than after 16 weeks. (33)

Another study published in May 2015 by Carlo Tornatore, et. al., now in extension, evaluated the efficacy of switching from Natalizumab to Dimethyl Fumarate. It evidenced several risk factors that might influence the diseases stability when switch- ing therapy: age ( $<60$ years of age were $1.8 x$ more likely to be unstable), sex (female patients were 2.9x more likely to be unstable) and treatment gap (8 or less weeks between Natalizumab and Dimethyl fumarate did not modify the disease stability. In conclusion the study proved that the majority of patients remained stable when switching from Natalizumab to Dimethyl Fumarate and the extension of this study is now in course to evaluate the MRI changes and relapse rate after the switch. (34)

An ongoing study that began in September 2015 by Northwestern New York Multiple Sclerosis Center is analyzing the effectiveness of switching MS patients treated with Natalizumb at risk for PML to Teriflunomide within the first 4 weeks after stopping the infusions. The study has so far recruited 15 patiens and the 6 months interim analysis showed that 13 of the 15 patients have stable MRI parameters with no new T2 enlarging hyperintensities. Although 2 patients presented contrast-enhancing lesions, teriflunomide was continued, in one case accompanied by short-term intravenous corticosteroids. There are no signs of PML in neither of the recruited cases. In conclusion the administration of Teriflunomide within the first 4 weeks form the last Natalizumab infusion proved safe and effective. (35)

Another theoretical model proposed by Prof. Dr. Gavin Giovannoni, is to switch patients from Natalizumab to Alemtuzumb. 3 scenarios are described based on risk of PML development. The first scenario was to immediately switch asymptomatic PML risk patients directly from Natalizumab to Alemtuzumab after a control MRI and CSF analysis - this is considered of being of high risk if carry-over PML develops. The second propose scheme, considered to be of intermediate risk, was to stop Natalizumab, have a 3 months gap during which Natalizumab will wash-out, have a baseline MRI, determination of JCV serology and then start of Alemtuzumab therapy. The last scenario, implies using a bridging therapy of 6-12 months with oral agents between Natalizumab last infusion and starting treatment with Alemtuzumab. It is theoretically considered to be of low risk, of low efficacy when considering disease relapses and also at risk of PML for using Alemtuzumab after the bridging agent. (36)

\section{CONCLUSION}

Several drugs used in MS treatment (Natalizumab, Alemtuzumab, Fingolimod, Dimethyl Fumarate) have reported cases of associated PML, most cases being secondary to Natalizumab treatment. 
Risk factors have been identified in order to evaluate PML risk in patients treated with Natalizumab (previous exposure to immunosuppressive medication, history of JC infection, Natalizumab use for more than 2 years and titre level of JCV antibodies), but no definite risk factors for the other drugs used to treat MS with reported cases of JC virus reactivation. Prolonged lymphopenia and an antibody index of $>0.9$ appear to favour PML development.

Routine screening of the antibody status and MRI should be performed in these patients.

\section{REFERENCES}

1. Tan C.S., Koralnik I.J. Progressive multifocal leukoencephalopathy and other disorders caused by JC virus: clinical features and pathogenesis. Lancet Neurol 2010; 9:425.

2. Engsig F.N., Hansen A.B., Omland L.H., et al. Incidence, clinical presentation, and outcome of progressive multifocal leukoencephalopathy in HIV-infected patients during the highly active antiretroviral therapy era: a nationwide cohort study. J Infect Dis 2009; 199:77.

3. Huang D., Cossoy M., Li M., et al. Inflammatory progressive multifocal leukoencephalopathy in human immunodeficiency virus-negative patients. Ann Neurol 2007; 62:34.

4. Berger J.R., Aksamit A.J., Clifford D.B., et al. PML diagnostic criteria: consensus statement from the AAN Neuroinfectious Disease Section. Neurology 2013; 80:1430.

5. Dang X., Vidal J.E., Oliveira A.C., et al. JC virus granule cell neuronopathy is associated with VP1 C terminus mutants. J Gen Virol 2012; 93:175.

6. Agnihotri S.P., Dang X., Carter J.L., et al. JCV GCN in a natalizumab-treated MS patient is associated with mutations of the VP1 capsid gene. Neurology 2014; 83:727.

7. Wüthrich C., Dang X., Westmoreland S., et al. Fulminant JC virus encephalopathy with productive infection of cortical pyramidal neurons. Ann Neurol 2009; 65:742.

8. Agnihotri S.P., Wuthrich C., Dang X., et al. A fatal case of JC virus meningitis presenting with hydrocephalus in a human immunodeficiency virus-seronegative patient. Ann Neurol 2014; 76:140.

9. Tan I.L., McArthur J.C., Clifford D.B., et al. Immune reconstitution inflammatory syndrome in natalizumab-associated PML. Neurology 2011; 77:1061.

10. Gheuens S., Smith D.R., Wang X., et al. Simultaneous PML-IRIS after discontinuation of natalizumab in a patient with MS. Neurology 2012; 78:1390.

11. Wüthrich C., Koralnik I.J. Frequent infection of cortical neurons by $\mathrm{JC}$ virus in patients with progressive multifocal leukoencephalopathy. J Neuropathol Exp Neurol 2012; 71:54.

12. Vermersch P., Kappos L., Gold R., et al. Clinical outcomes of natalizumab-associated progressive multifocal leukoencephalopathy. Neurology 2011; 76:1697.

13. Sahraian M.A., Radue E.W., Eshaghi A., et al. Progressive multifocal leukoencephalopathy: a review of the neuroimaging features and differential diagnosis. Eur J Neurol 2012; 19:1060.

14. Yousry T.A., Pelletier D., Cadavid D., et al. Magnetic resonance imaging pattern in natalizumab-associated progressive multifocal leukoencephalopathy. Ann Neurol 2012; 72:779.

15. Arnaud F.X., Hissene A., Métivier D., et al. Gadolinium enhancement in brain magnetic resonance imaging in progressive multifocal leukoencephalopathy after natalizumab monotherapy: is it really atypical? J Neuroradiol 2012; 39:267.

16. Chalkley J., Berger J.R. Progressive Multifocal Leukoencephalopathy in Multiple Sclerosis. Curr Neurol Neurosci Rep 2013; 13:408
To date, there is no specific treatment for this condition, MS medication causing the complication needs to be discontinued and the measures and drugs used has the role of restoring the patient's immune system in order to naturally fight and eliminate the virus.

Even if PML remains a rare complication in this setting, its course is usually severe, having a reported mortality rate of $23 \%$ and more than half of its survivors have moderate to severe neurological disability.

17. Cinque P., Scarpellini P., Vago L., et al. Diagnosis of central nervous system complications in HIV-infected patients: cerebrospinal fluid analysis by the polymerase chain reaction. AIDS 1997; 11:1.

18. Hutchinson M., Natalizumab: A new treatment for relapsing remitting multiple sclerosis. Ther Clin Risk Manag. 2007 Jun; 3(2): 259-268.

19. Giovannoni G., Clinic Speak: What is a high PML risk? , available at http://multiple-sclerosis-research.blogspot.com/2014/01/clinic-speakwhat-is-high-pml-risk.html

20. Kelly J. Baldwin, Jeffery P. Hogg, Progressive Multifocal Leukoencephalopathy in Patients With Multiple Sclerosis, Curr Opin Neurol. 2013; 26(3):318-323.

21. Schroder A., Lee D.H., Hellwig K., et al. Successful management of natalizumab-associated progressive multifocal leukoencephalopathy and immune reconstitution syndrome in a patient with multiple sclerosis. Arch Neurol 2010; 67:1391.

22. Elphick G.F., Querbes W., Jordan J.A., et al. The human polyomavirus, JCV, uses serotonin receptors to infect cells. Science 2004; 306:1380

23. Ray U., Cinque P., Gerevini S., Longo V., Lazzarin A., Schippling S., Martin R., Buck C.B., Pastrana D.V. JC Polyomavirus Mutants Escape Antibody-Mediated Neutralization. Science Translational Medicine. September 23, 2015. Doi:10.1126/scitransImed.aab1720

24. Jelcic I., Combaluzier B. Jelcic I., Faigle W., Senn L., Reinhart B.J., Ströh L., Nitsch R.M., Stehle T., Sospedra M., Grimm J., Martin R. Broadly neutralizing human monoclonal JC polyomavirus VP1-specifc antibodies as candidate therapeutics for progressive multifocal leukoencephalopathy. Science Translational Medicine. September 23, 2015.

25. Chun J., Hartung H.P., Mechanism of action of oral fingolimod (FTY720) in multiple sclerosis, Clin Neuropharmacol. 2010 Mar-Apr;33(2):91-101. doi: 10.1097/WNF.0b013e3181cbf825.

26. Douglas R. Jeffery, Clyde E. Markowitz, Anthony T. Reder, Bianca Weinstock-Guttman, Kathy Tobias, Fingolimod for the Treatment of Relapsing Multiple Sclerosis, Expert Rev Neurother. 2011; 11(2):165-183.

27. Sinnecker T., Othman J., Kühl M., Mekle R., Selbig I., Niendorf T., Kunkel A., Wienecke P., Kern P., Paul F., Faiss J., Wuerfel J. 7 T $\mathrm{MRI}$ in natalizumab-associated PML and ongoing MS disease activity: A case study. Neurol Neuroimmunol Neuroinflamm. 2015; 2(6):e171.

28. Nelda Murri, Dimethyl Fumarate (TECFIDERA): A New Small Molecule Disease-Modifying Drug for Multiple Sclerosis, available at http://www.medscape.com/viewarticle/821109

29. Linker R.A., Gold R., Dimethyl fumarate for treatment of multiple sclerosis: mechanism of action, effectiveness, and side effects. Curr Neurol Neurosci Rep. 2013 Nov; 13(11):394. doi: 10.1007/ s11910-013-0394-8. 
30. Fox R.J., Kita M., Cohan S.L., Henson L.J., Zambrano J., Scannevin R.H., O'Gorman J., Novas M., Dawson K.T., Phillips J.T., BG-12 (dimethyl fumarate): a review of mechanism of action, efficacy, and safety. Curr Med Res Opin. 2014 Feb;30(2):251-62. doi: 10.1185/03007995.2013.849236. Epub 2013 Oct 22.

31. Hu Y., Turner M.J., Shields J., Gale M.S., Hutto E., Roberts B.L., Siders W.M., Kaplan J.M., Investigation of the mechanism of action of alemtuzumab in a human CD52 transgenic mouse model. Immunology. 2009 Oct; 128(2):260-70. doi: 10.1111/j.1365-2567.2009.03115.x.

32. Tobias Ruck, Stefan Bittner, Heinz Wiendl, Sven G. Meuth, Alemtuzumab in Multiple Sclerosis: Mechanism of Action and Beyond. Int. J. Mol. Sci. 2015, 16(7), 16414-16439; doi:10.3390/ ijms160716414

33. Kappos L., Radue E.W., Comi G., Montalban X., Butzkueven H., Wiendl H., Giovannoni G., Hartung H.P., Derfuss T., Naegelin Y., Sprenger T., Mueller-Lenke N., Griffiths S., von Rosenstiel P., Gottschalk R., Zhang Y., Dahlke F., Tomic D.; TOFINGO study group, Switching from natalizumab to fingolimod: A randomized, placebo-controlled study in RRMS. Neurology. 2015 Jul 7; 85(1):2939. doi: 10.1212/WNL.0000000000001706. Epub 2015 May 29.
34. Faria S. Amjad, Nasima Afsari, Carlo Tornatore, The Safety and Efficacy of Switching from Natalizumab to Dimethyl Fumarate: Real World Experience. Available athttps://cmsc.confex.com/cmsc/2015/ webprogram/Paper3382.html

35. Switching Relapsing Multiple Sclerosis Patients Treated With Natalizumab at Risk for Progressive Multifocal Leukoencephalopathy to Teriflunomide: Is This Safe and Effective?, available at https:// clinicaltrials.gov/ct2/show/NCT01970410?term=teriflunomide\&rank=5

36. Giovannoni G., Clinic Speak: switching from natalizumab to alemtuzumab. Available at http://multiple-sclerosis-research.blogspot. com/2014/05/clinic-speak-switching-from-natalizumab.html

37. Koralnik J.I., Gonzalez-Scarano F., Dashe F.J. Progressive multifocal leukoencephalopathy: Epdemiology, clinical manifestations, and diagnosis. Available at www.uptodate.com

38. Faulkner M. Risk of progressive multifocal leukoencephalopathy in patients with multiple sclerosis. Expert Opin Drug Saf. 2015 Nov;14(11):1737-48. doi: 10.1517/14740338.2015.1093620. Epub 2015 Sep 22. 